\title{
Progressions in Ornamented Doors of Domestic Buildings in Yorubaland
}

\author{
Foluso Modupe ABEJIDE \\ Department of Fine and Applied Arts, Obafemi Awolowo University, Ile-Ife, Osun-state, Nigeria
}

\begin{abstract}
Doors are accompaniments of buildings and always the first point of contact by visitors to buildings. Because of this, doors especially the main doors "ilekun abawole,"are always elaborately embellished to make them aesthetically pleasing and welcoming. The imagery on doors among the Yoruba of Nigeria and the techniques of making them visually appealing, aesthetically functional and strong, differ with materials and periods of history. This paper studies the progression in the use and beautification of doors, in Osogbo, Yorubaland, with the view to revealing the forms at its inception as well as the changes in materials, forms, and motifs with time. The study concluded that the materials, forms, and motifs on doors evolved over periods in history, each giving way to new styles and images as the peoples' exposure, experiences and socio-cultural values broaden.
\end{abstract}

Keywords: Advancement, Doors, Aesthetics, Domestic buildings, Yorubaland.

DOI: $10.7176 / \mathrm{JCSD} / 55-01$

Publication date: January $31^{\text {st }} 2020$

\section{Introduction}

Doors (aruru or ilekun enu ona), are significant elements of modern domestic buildings in Yorubaland. They served as movable barriers which conceal and protect the residents from intrusion of animals, insects and unwanted guests (Bewaji, 2003:151). They also beautify buildings, while communicating to people about the owners' philosophies, religious and socio-political status. The importance of doors in Yoruba culture is highlighted in the excerpt: "Ile ti ko ni ilekun, ni asinwin nwo", meaning: buildings without doors are easily accessed by miscreants and mad people. Part of the cognomen of Iwo people of Osun-State, reads: "Iwo ti ko ni le'kun, ti ko ni kokoro" which implies that they are descendants of people who neither had doors nor locks". However, investigations show that their progenitors' avoidance of usage of doors in the time immemorial emanated from their possession of many slaves who kept watch on their valuables. Doors therefore are indispensable in buildings.

\section{Research Methods}

The primary data for this study were obtained through field investigations, physical observation and photographic survey of selected relevant doors to the study. Hand drawn illustrations were also used to generate data for the study. Custodians of history were consulted to elicit information on the forms at the inception, while secondary data from relevant literature were utilized to corroborate the interviews. The number of relevant ornamented doors in the study area is endless and immeasurable, however seventeen (21) doors and fifteen (15) fanlights that show progression in the aesthetics of doors were purposively selected.

\section{Origin and Forms at the Inception}

Investigations revealed that before the advent of doors in the pre-historic era, entrances of buildings were covered with colourful mats (eni ore, or awèrè, Figure 1). Such mats were made aesthetically pleasing, with plant stains in assorted colours. Entrances of the buildings were safeguarded with èkùré iséyò (assemblages of jinglers), made with woven palm veins, bamboos or raffia to which empty snail shells, (and in more recent times, empty tins and scrap metals) were attached. These objects make clattering sounds, capable of alerting residents of the presence of intruders at night (Oladunjoye, Oral $\mathrm{com}^{1}$ ). Dramatists' scenes which are always based on pains-taking research into required aspects of culture often show mat covered entrances. The use of mat for screening / covering entrances of Yoruba dwellings is corroborated by Eyo (1979:71). The mats covered entrances were said to be later replaced with wooden doors (aruru or ilèkùn, starting with, ilekun abógundé, which were solid wooden doors connected to buildings with wooden pegs (Figure 2). Denyer (1978:89) records the 'pivoting of carved doors on protruding pegs at the top and bottom', around 1910. The name of the 'Abogunde' door type according to Chief Ifayemi Elebuibon, ( oral $_{\text {com }}{ }^{2}$ ), emanates from the earliest ones being produced by the carvers guild from the Ajíbógundé lineage.

\section{Progression in the Use of Doors}

Changes in the aesthetics of buildings in the early colonial period however started with the introduction of (ilekun alugbagba), which was probably ushered in by the Europeans in replacement of the abogunde types. The Yoruba name alugbagba is suggestive of the sound they make at closing, and reference to the alugbagba door 
type is found in Abrahams (1958:52). From then, doors of eminent peoples' buildings, as well as the portals and posts supporting their verandas or holding their roofs, used to be embellished with carved figurative narrations in solid wood (Figure 3). The richer the owners of the buildings are, the more elaborate their enrichments with carvings.

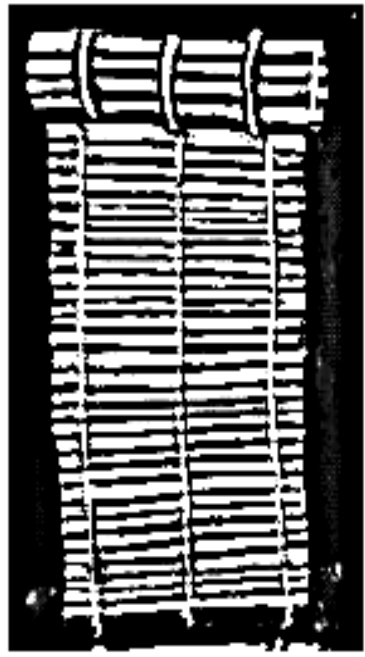

Figure 1: An entrance covered with mat, (Illus: Abejide, 2019).

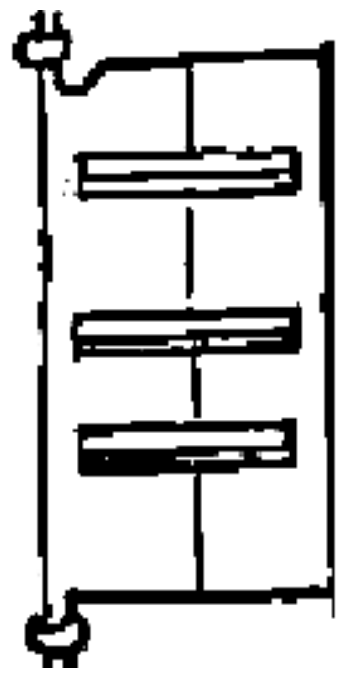

Figure 2: Flushed wooden door with wooden pegs, (Illus: Abejide, 2019)

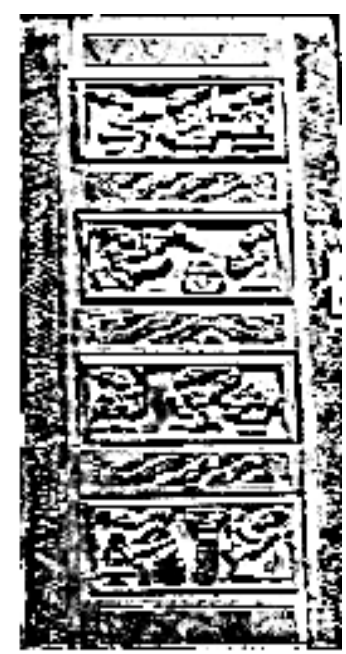

Figure 3: Carved wooden door with narrations, (Photo: Abejide, 2019).

Later, the rich peoples' flushed doors which used to be elaborately carved with images gave way to simple light paneled geometrical designed wooden doors (ilekun olopon, Figure 4). From this time on, doors were simple, in light wood or assemblages of woods, enhanced with both indigenous and foreign-influenced styles. The Europeans also introduced carving of jambs (wooden support for doors), as part of elaboration of doors. These were embellished with fill-in designs, patterned webs (Figure 4), and assemblages of centric graduated baguette designs or specific reoccurring designs. An example is the jamb with linear grooves in figure 5, obviously made possible by the availability and use of sophisticated carpentry devices. Common dominant forms in the ornamentation of doors at the early times were geometric shapes such as triangles, lozenges, oval, and sometimes mimesis of cocoa pods. These forms were used alone or sometimes further enclosed with other motifs such as doves, human hands, or flowering plants, in various presentations. Some doors are filled with add-ons such as pegs and turned wood or timber louvers.

\subsection{Afro-Brazilian Elaboration of Ornamentation on Doors}

Ornamentation on doors later further assumed highly sophisticated, stylized and abstracted forms, with more varied motifs ushered in during the Afro-Brazilian era. Featuring as main motifs on doors at this time were heart shapes, shields, and badges, which are European offshoots, while some doors were still adorned with pods and geometric shapes like the earlier times. These main forms were also sometimes enclosed with other images such as plants, single, dual or triple recurrent heart shapes, as well as stars and ribbons, which are also European derivatives.

The Afro-Brazilian era also ushered in doors with intricate forms, as well as more elaborate, sophisticated, innovative and wilfully stylized forms. This is evident in wooden door with stylized flowers and tendrils, such as the door with carvings at the lower half and textured multi-coloured glasses at the upper panes (Figure 6). 


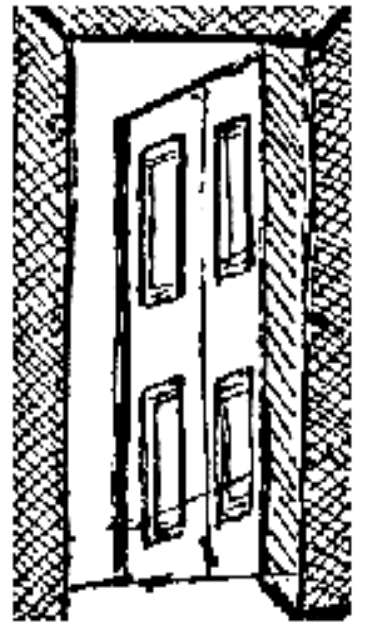

Figure 4: Jamb with patterned web of lozenges (Illus: F.M. Abejide, 2019).

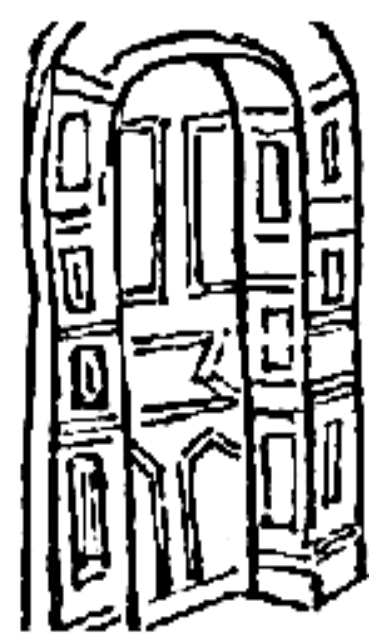

Figure 5: Light panelled designed door

(Illus: Abejide, 2019).

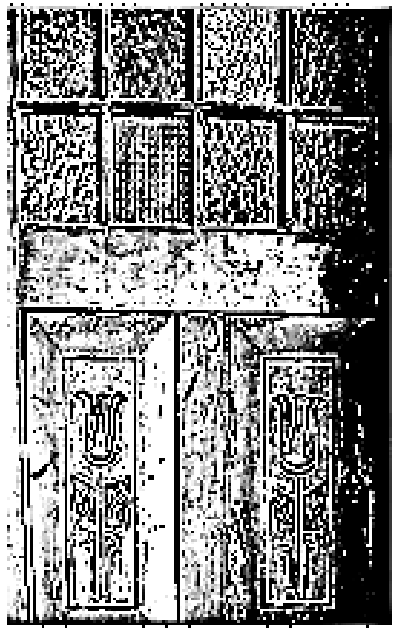

Figure 6: Door with stylized plants and multi-coloured textured glasses

(Photo: Abejide, 2019).

\subsection{Introduction of skylight windows on door frames}

Fixed or permanent rectangular or semi-circular windows called the fanlight or skylight windows were introduced to the top of door frames, below the transom or lintel (the beam over the window) for aesthetics and illumination. The forms illuminating and further embellishing fanlights ranged from wooden punches (Figure 3a), circular die-cuts (Figure 3b), linear die-cuts (Figure 3c), open-work lozenges (Figure 3d), horizontal slat wood panelling (Figure 3e) and linear crisscross matting (Figure 3f). Figure $3 \mathrm{~g}$ shows a fanlight with the edge patterned with intricate convoluting planks, while Figure $3 \mathrm{~h}$ has three rows of inverted sickles. However, Figure $3 \mathrm{i}$ has rows of wooden pegs, with the arrangement forming a philosophical text and written prayer in Yoruba language which reads: "Ma feyi s'opin Oluwa," meaning: May this not be the end of my achievements oh Lord.

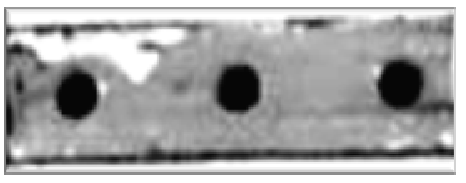

Figure $7 \mathrm{a}$

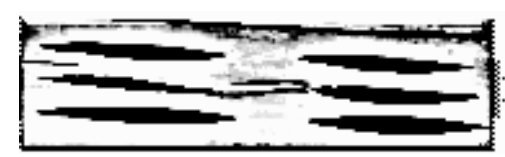

Figure $7 \mathrm{~d}$

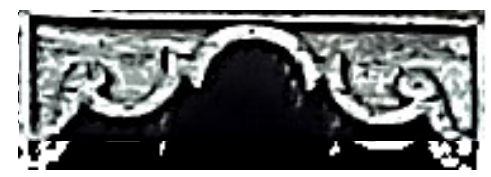

Figure $7 \mathrm{~g}$

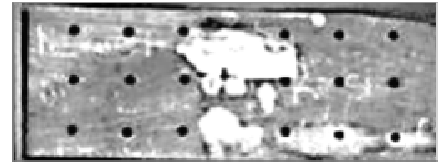

Figure $7 \mathrm{~b}$

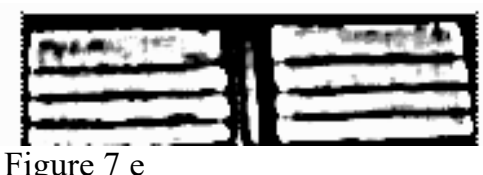

Figure $7 \mathrm{e}$

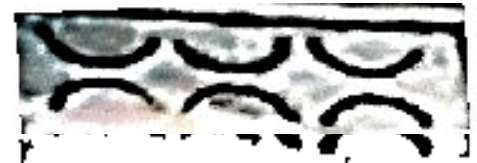

Figure $7 \mathrm{~h}$

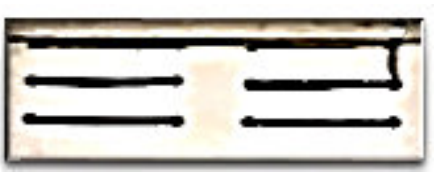

Figure $7 \mathrm{c}$

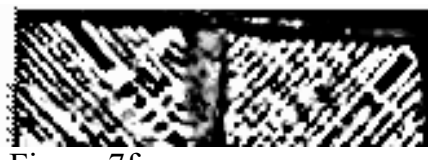

Figure $7 \mathrm{f}$

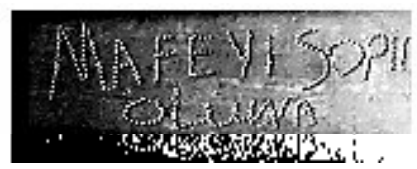

Figure $7 \mathrm{i}$

Figure 7a-i: Variations of adornments in wooden fanlights (Photo: Abejide, 2019).

4.2.1 Glass skylight windows in wooden panes

Fanlight windows on doors were later embellished with plain, tinted transparent or textured glasses, set in wooden panes. The glasses were further ornamented by varying the mutins (the thin cross wood holding the window pane in place). Mutins vary from single glass panes to glasses set in two vertical mutins, sandwiched between horizontal mutins, and mutins with two inverted bends ending in vertical strokes at both ends (Figure 4a), curvatures joined by a horizontal strip (Figure 4b), and glasses set in rosettes (Figure 4c). 


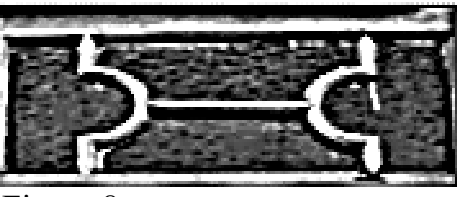

Figure 8a

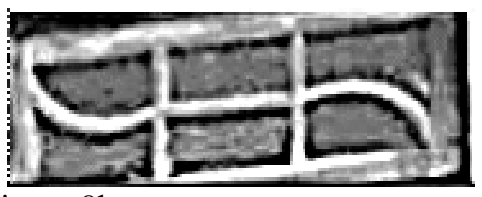

Figure $8 \mathrm{~b}$

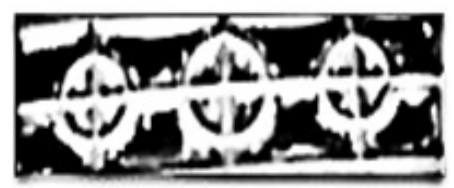

Figure 8c

Figure 7a-c: Some mutins designs on glass fanlights (Photo:Abejide, 2019).

4.2.2 Paint Embellished Fanlights

The adornments of fanlights later advanced to the use of painted glasses. Some of the glass fanlights found are in the intermediate zones are adorned with painted philosophical writings and flowers (Figures 5a-c). These from the dates written on some of the buildings where they are found, reigned between the 1950s and 1960s.

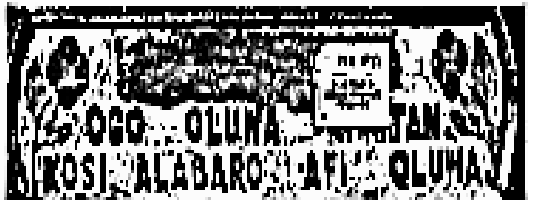

Figure $9 \mathrm{a}$

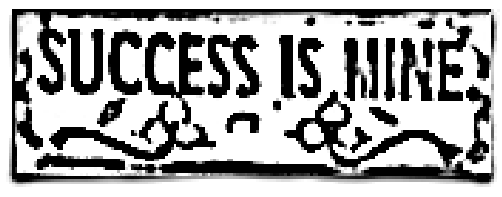

Figure $9 b$

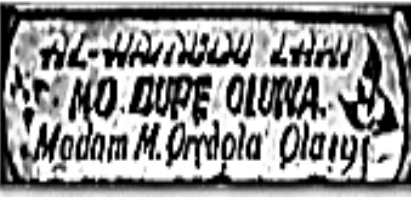

Figure 9c

Figure 9a-f: Some glass fanlights with painted texts and flowers (Photo: Abejide, 2019).

The use of doors affixed with fanlights became the in-thing, before the introduction of the prefabricated imported casement glass doors encased in steel frames. The aesthetic variation in the casement doors often depend on the textures of the glasses and the distance between the metal frames. This use of casement doors was in line with the "International Style", a global trend opposed to the use of ornamentation, and advocating for the exclusion of all forms of decorations from buildings except only the purely functional and structurally necessary features (Alli,1993:21 and Okpako \& Amole, 2005:71-72). The casement doors were embraced in homes of elites at the time.

\section{Re-birth of the Use of Carved flushed wooden Doors}

The re-enactment of the use of carved flushed doors is observed in some post-modern buildings. They were inspired by the indigenization campaign of the pre-independence nationalist and Pan-Africanism from the 1920s, advocating for the de-emphasis of the European culture, in favour of the country's rich heritage (Vidal 2002:17). This climaxed between the 1940s and 1950s, and coincided with Rev.Fr. Kevin Carol and O' Mahoney's reintroduction of earlier condemned traditional carved doors and images for ornamenting Catholic churches, in parts of Ekiti, Ondo, Ijebu and Ibadan, between 1947 and 1949. The back to traditional carved flushed wooden doors with narratives, in domestic buildings was spare headed by Susanne Wenger in her residence in Oke-Baale Osogbo, in the 1950s, as part of her rejuvenation efforts for a return to cultural ideals. Many people lauded Wenger's move towards the historical styles, and her advocacy of a re-enactment of Africanisms of domestic buildings. This stimulated the peoples' sense of pride, stirring their artistic and cultural consciousness, culminating in the use of carved wooden doors in the indigenous style, in residences of elites. These doors adorned the main entrances, existing concurrently with the panelled doors which were cheaper, in other entrances. Worthy of note is the high relief central kingly figure in plate 6 , which is a new development in door ornamentation and means of emphasising prominent figures.

\section{New Approaches to Doors}

There are new approaches to the designing of doors from the 1980s, these are discussed below:

\subsection{Manually designed Iron Doors}

High incidences of robbery led to the introduction of skeletal iron works in the 1970s, and later the use of strong doors, made of sheets of welded iron, embellished with square pipes or rods, These came in array of designs varying from convoluting forms, angular, linear or curvilinear carved presentations, to cubic tile like designed surfaces. They sometimes have plain smooth surfaces or textured patterned surfaces depending on the texture of the metal plates used. The plain sheets are further designed by embedding them with construction of hollowed forms, or by designing it with flora or abstracted forms with thin rods or flat bars. They are also at times highlighted with gold or silver, which contrast with the colour of the metals (Figure 11). The preferences for iron doors emanated from their strength which gives assumption of assurance for security.

\subsection{New Classes of Wooden Doors}

Carved wooden doors are still in use, but in various innovative styles, with advances and influx of ideas encouraged by globalization. The assortment of wooden doors in the contemporary times range from flushed wooden doors with carved decorations, the pyrographic doors, doors with decorative wooden assemblages and 
wooden doors embellished with add-ons. These various types are elaborated below:

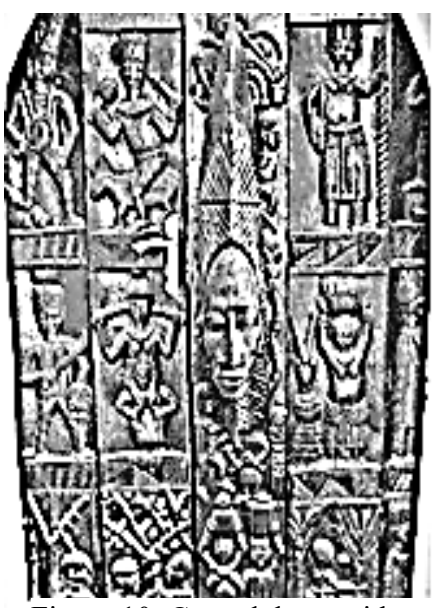

Figure 10: Carved door with

1 central image in high relief (Photo: Abejide, 2019).

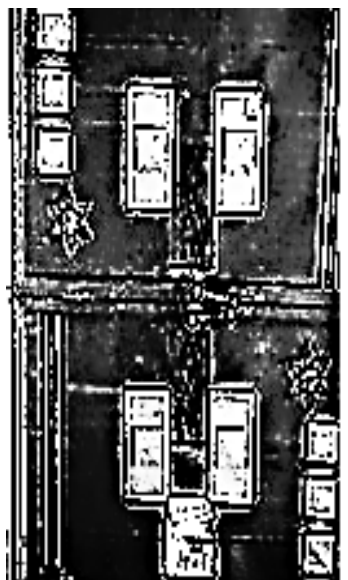

Figure 11: Gold painted iron door

(Photo: Abejide, 2019).

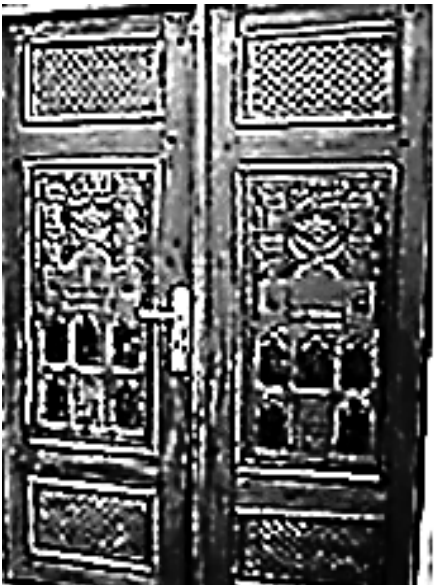

Figure 12: A Pyrographic Door with the image of a mosque (Photo: Abejide, 2019).

\subsubsection{Wooden Doors with Carved Decorations}

The carved doors in the post-modern times are eclectic, combining ideas from earlier periods, and added innovation of the new period. An example is the re-enactment of carving with narratives; however the door in plate 6 has an innovative embossment of its central figure which is unique to the new era. Many modern carved doors feature the use of geometric forms, European icons such as dove, shields, or heart icon, forms derived from Christianity such as dove, crosses or open book, as well as Islamic religious icons like the crescent and the moon. Some doors also feature traditional symbolic forms such as horse whisks, crowns, stringed beads, snails and guilloche designs.

\subsubsection{The Pyrographic Doors}

Pyrographic doors are advances in door ornamentation, with designs achieved by burning the backgrounds of decorative forms, leaving the surfaces of the motifs in contrasting black colour against the natural brown colour of the wood (Figure 12). This appears to be a new innovation introduced after the 1960s.

\subsubsection{Doors with Decorative Wooden Assemblages}

There are decorative assemblages composed from symbolic forms, such as stars, quadrilaterals, rosettes, banisters and machine turned circular planks, sometimes used alone or with other add-ons. These are glued or nailed to door frames for beautification. Figure 13 showcases an inventive spraying of edges of attached motifs, highlighting the vital areas in black, yielding a result close to pyrography. Figure 14 shows similar and unique nailing of assembled flat cut-out images composed on a flat black board, to form a mosque and stars, yielding a contrasting design close to the pyrographic method. In Figure 15 is a carved relief depiction of the crucified Christ surrounded by angels, glued to a board painted in black. It yields a result similar to the nailed cut-outs in Figure 14. 


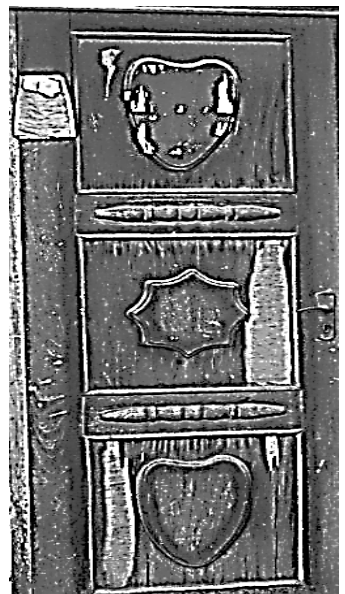

Figure 13: Door with assemblages sprayed in black for highlight

Photo: Abejide, 2019).

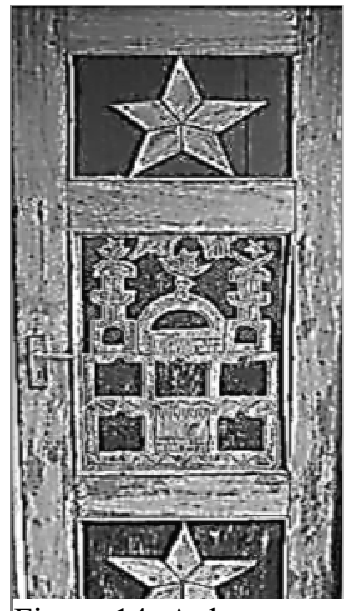

Figure 14: A door with forms nailed to a painted board (Photo: Abejide, 2019).

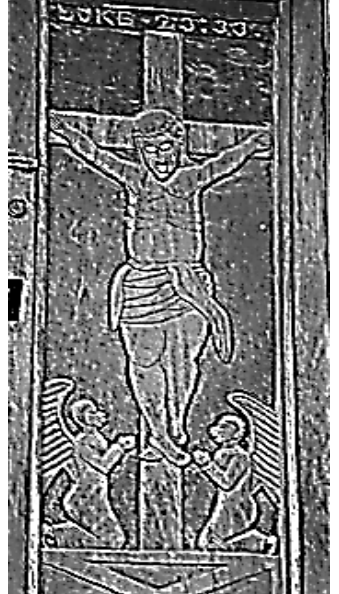

Figure 15: Door with carved forms glued to a painted background (Photo: Abejide, 2019).

\subsubsection{Wooden Doors Designed with Add-ons}

In this category of add-ons decorating doors are circular machine turned planks and rows of tar-rods. Tar-rods generate rectilinear forms, inverted vertical zig-zag shapes in opposite directions, and squares, resulting in a textile like spread (Figure 16). There are also tar rods in alternate placement, giving a rhythmic flow of diagonal arrangement, while some are made to imitate iconic forms, such as the guilloche form in figure 17. Figure 18 presents an innovative alternation and tilling of square and cylindrical turned planks on a flat board, giving an interesting contrasting all over pattern. Some doors are further enhanced with fill in textures and border designs, ranging from ropes designs, hachures, scrolls, lozenges, blades forms, dots, checkers and punches.

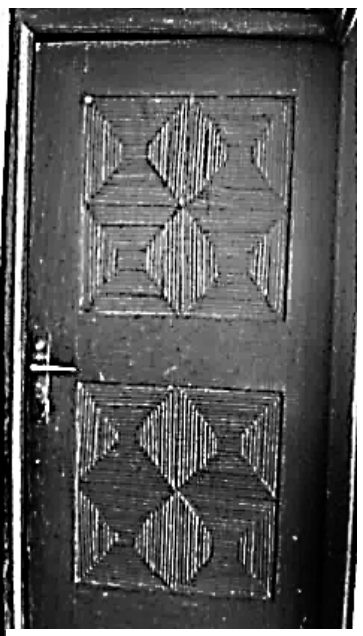

Figure 16: A door designed with rows of tar-rods on a flat board (Photo: Abejide, 2019).

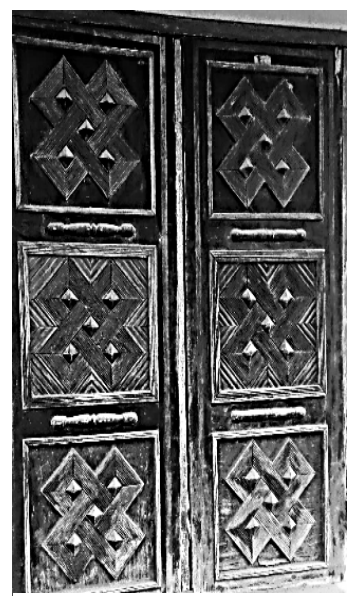

Figure 17: Door adorned with tar-rod forming a guilloche design (Photo: Abejide, 2019).

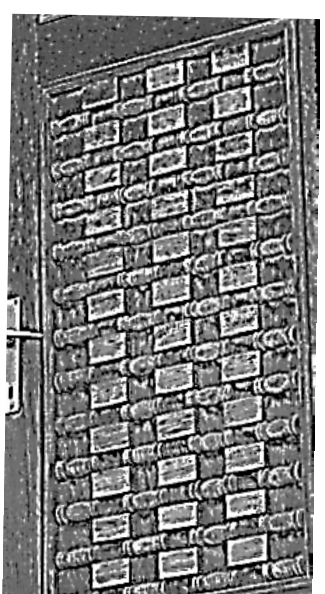

Figure 18: Turned banisters and square planks on a flat board (Photo: Abejide, 2019).

\subsection{Imported Prefabricated Plastic Laminated Doors}

In the postmodern era, usage of glass doors encased in aluminium frames is common. They are either of the shutter closed type or casement sliding sideways. The aesthetic variations in these doors depend on the shades or colours of the glasses, the textures and patterns on them, as well as the distance between the connecting metal frames (Figure 19). Also widespread are imported prefabricated doors (known as bullet proof doors). The so called bullet proof doors are of two types: the wood packed lustre plastic laminated or veneered doors, which are cheaper and affordable to many (Figure 20) and the concrete filled bullet proofs doors (Figure 21). Both are in a wide array of patterns ranging from abstractions, to geometric and floral motifs. 


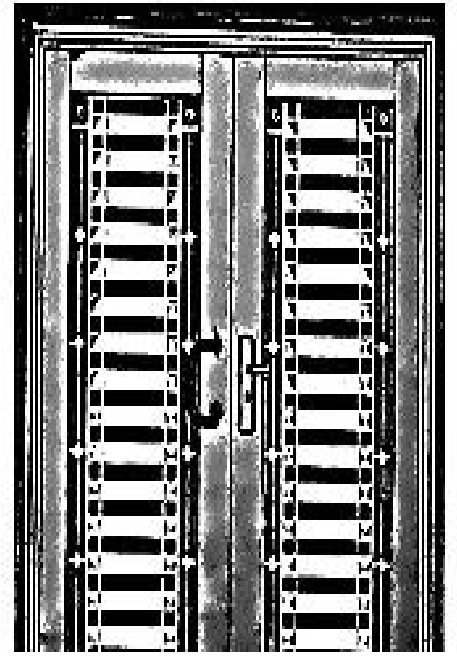

Figure 19: A trendy ornamental glass door with simple plastic geometric design

Photo: Abejide, 2019).

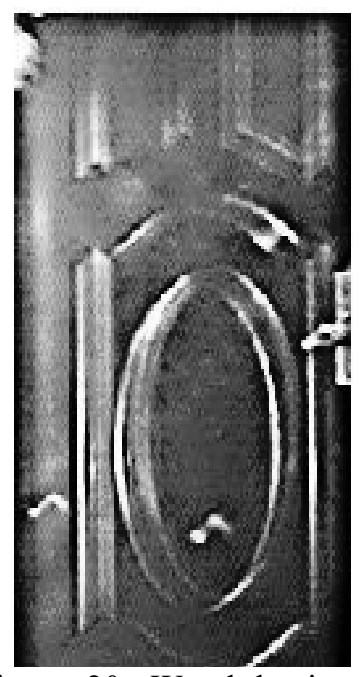

Figure 20: Wood laminated veneered door

(Photo: Abejide, 2019).

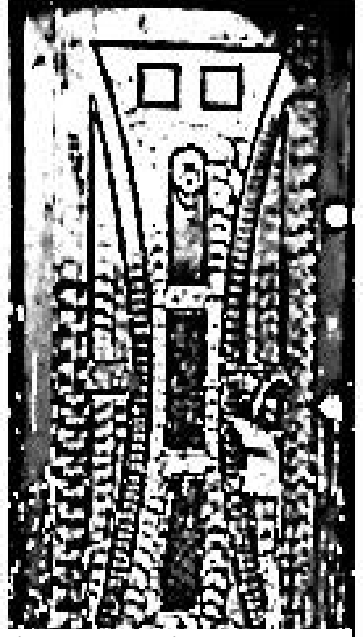

Figure 21: The concrete filled bullet proof door (Photo: Abejide, 2019).

Although smart and glossy, the beauty of the plastic laminated or veneered doors seems to be superficial. Despite their gleam, which make people easily carried away, these laminated plastic doors with their mechanical features appear to be retrogression from the earlier solid carved doors with complex innovative designs. They are also held to be prone to termite attacks, which makes them not to be aesthetically apt. This is because aesthetics is not about outer beauty alone, but a combination of beauty and utility. These type of doors are comparable to flirtatious maidens held to be engaged in fashion! or decaying fruits that people presume are getting ripe! (Ogede to nbaje, won lo npon, omoge ndoko, won lo nsoge.

This study does not however totally condemn the use of the plastic laminated doors, as investigation reveal that they can now be fabricated locally, since the outer pre-designed sheets of plastic are now in the market. The study advocates the construction of such doors, which will afford builders the opportunity of ascertaining that the right type of wood, which is termite resistant is used in replacement of the prefabricated ones, and that such planks are well treated before they are sealed off. The locally fabricated types should also be cheaper, while generating income for local artisans.

\subsection{Automated Iron Doors}

After the laminated doors emerged sheets of strong metals in a wide assortment of prefabricated designs that are assembled locally. They produce mechanical designs that are mimetic of the laminated automated doors, thus combining strength and beauty, hence utility (Figure 22). Similarly, Figure 23 shows an innovative pasting of marbles as background for linear rosette design in welded metal doors, which is also an expansion of the predesigned metal assembled doors. More designs are emerging in ornamentation of doors as both carpenters and welders copy the designs on imported doors to fabricated wooden or metal doors. 


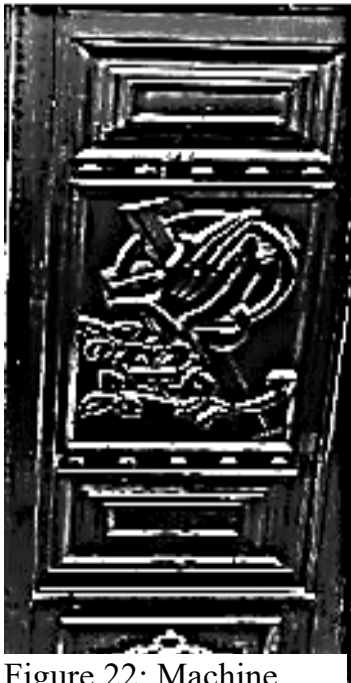

Figure 22: Machine embossed iron door Photo: Abejide, 2019).

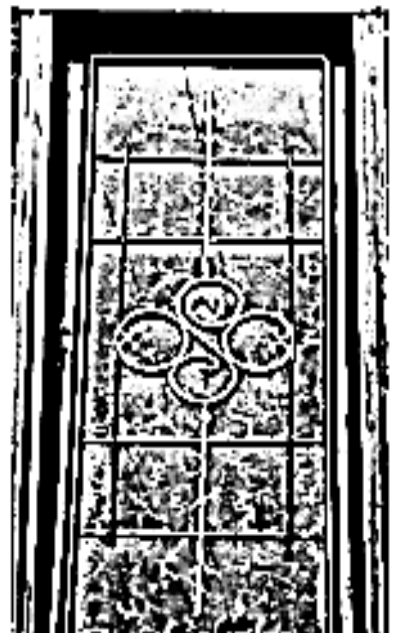

Figure 23: Marble coated iron door

(Photo: Abejide, 2019).

\subsection{Metal Repoussé}

The search for unique accessories and forms in the beautification of buildings led to the innovative use of metal repoussé, a relief design produced by hammering designs into the surface of flat aluminum. The innovative metal repoussé door encased in elaborately carved jamb in the main entrance of Elebuibon's new building, Ayetoro, Osogbo (Plate 20), is embellished with traditional motifs and forms upholding the myths of origin and culture of the town. The use of metal repoussé doors as ornamentation feature in domestic buildings appears to be a new development inspired by Adébísí Àkànjí's innovation in the Mbábi-Mbáyò art workshop, organized by Ulli Beier in the !960s. Similar attempt at metal repoussé was made by late Professor Agbo Folárìn, at the conference center of the Obáfémi Awólówò University, Ilé-Ifè, where it was only used to embellish a space. The utilization of metal repoussé in the enrichment of buildings according to Oyèlolá, (2010:282-3) is sustaining the Òsogbo workshop art, while promoting the artists who make them.

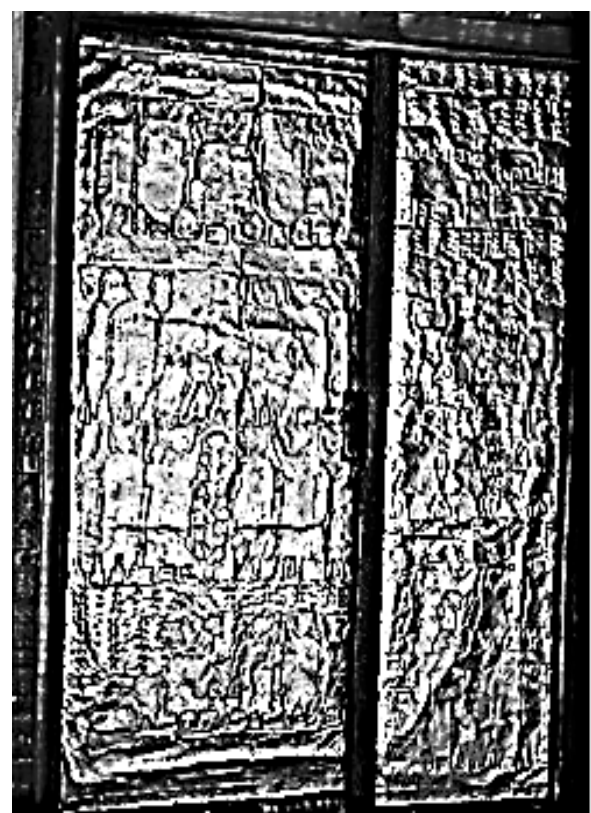

Figure 24: Aluminium Repouseé door (Photo: Abejide, 2019).

\section{Summary of Findings, and Concluding Discussion}

This paper has traced the origin, growth and progression in the use of doors in domestic buildings in Osogbo, and by extension Yorubaland, from the earliest time till the present. In addition to examining the advances in the 
enrichment and utility of the doors, it tries to classify the types of doors used in domestic buildings, while taking into consideration the factors responsible for the changes at different eras. Findings of the study reveal that despite their elegance, many of the doors used in the contemporary period are fragile and lack the solidity of the earlier times. The study argues that doors should both be visually appealing and strong for them to be aesthetically pleasing. It concludes that the materials, forms, and motifs on doors evolved with periods of history, as well as the peoples' exposures and changes in their socio-cultural values. The study recommends that there should be museums where doors and other important accessories in buildings are displayed as part of the material culture of the people. The exhibition of both the old and new architectural accessories will complement the efforts of the Nigerian museum of traditional architecture (MOTNA) in documenting Nigerian heritage for posterity.

\section{REFERENCES}

Abraham R.C. (1958). Dictionary of Modern Yoruba, London University Press, 52, 304.

Alli, T.A. (1993). "Post modernism in Nigeria a case for Eclectism", (Unpublished Masters. Thesis), Department of Architecture, Ile-Ife: Obafemi Awolowo University, 21.

Bewaji, J.A.I. (2003). Beauty and Culture, Ibadan: Kenbin Press Ltd, 151.

Denyer, S. (1978). Traditional African Architecture, an Historical and Geographical Perspective, London Heinemann, 89.

Eyo, E. (1979). Nigeria and the Evolution of Money, The Central Bank of Nigeria, 71-72.

Okpako, J. and Amole, B. (2005). "Globalization, Modernity and Architecture: Modern Architecture in Ibadan After 1960", in Fadare et. al. (ed.) Conference Proceeding on Globalisation and Culture in the Nigerian Built environment, Vol II, Faculty of E.D.M., Ile-Ife: Obafemi Awolowo University, 71.

Vidal, A.O. (2002). The Institunalization of Western Music Culture in Nigeria, and The search For National Identity: Inaugural Lecture Series No. 161, Obafemi Awolowo University Press, 17.

Oyelola, P. (2010). Nigerian Artistry, Ibadan, Mosuro Publishers, 282-283.

\section{Notes}

1. Oral communication with Elder Oladunjoye, Emmanuel (aged 83), Parakin, Ile-Ife.

2. Oral communication with Chief Elebuibon, Ifayemi (Awise of Osogbo, aged 76) Ayetoro, Osogbo. 